$5-28-2021$

Postdischarge 24/7 hotline service for neurology and neurosurgery patients and 1-year impact on readmission rates, unplanned emergency department visits, and patient satisfaction

Shafqat Bibi

Rida Mitha

Kiran Bano

Farida Datoo

Nadia Karim

See next page for additional authors

Follow this and additional works at: https://ecommons.aku.edu/pakistan_fhs_son

Part of the Diseases Commons, Health Information Technology Commons, Neurology Commons, Neurosurgery Commons, and the Nursing Midwifery Commons 
Authors

Shafqat Bibi, Rida Mitha, Kiran Bano, Farida Datoo, Nadia Karim, and Muhammad Shahzad Shamim 


\title{
Postdischarge 24/7 Hotline Service for Neurology and Neurosurgery Patients and 1-Year Impact on Readmission Rates, Unplanned Emergency Department Visits, and Patient Satisfaction
}

\begin{abstract}
Objective: Telephone triage is a system in which trained nurses use standardized protocols to evaluate symptoms over the phone and determine the appropriate course of action. Materials and Methods: We implemented a protocol for systematic follow up phone calls and telephonic triage to families of neurology and neurosurgery patients after discharge, primarily to improve care transition and to assess its impact on the ratio of visits in the emergency department, readmissions, and overall satisfaction of patients and families. The intervention comprised the implementation of nurse led telephone triage and postdischarge follow up phone calls. After implementing hotline services in mind and brain service line, a retrospective cohort study was conducted to evaluate the impact of hotline services on patient readmissions, emergency department visits, and overall satisfaction rate. We collected data of readmission rate and emergency visits of discharge patients in three periods a prehotline period, immediate posthotline period, and late posthotline period to make comparison. Patients discharged home from the neurology and neurosurgery services from January 2017 to September 2019 were provided with hotline number to call in case of any issue or query. These patients also received postdischarge follow up calls from hotline nurses. We initiated the hotline in October 2017. Results: On analysis, we found a $25 \%$ decline in readmission rate in the immediate period of hotline followed by a further decline to $37.2 \%$ in the late period as compared to the prehotline period. Among discharge patients visiting the emergency department, we found a decline of $18.5 \%$ in the immediate posthotline period which further declined to $77.7 \%$ in the later phase as compared to the prehotline period. Conclusion: A standardized telephone system and pathway can be an effective way to improve nurse-patient communication which can further improve health outcomes for many patients.
\end{abstract}

Keywords: Hotline, quality initiative, readmission, telephonic triage

\section{Introduction}

Transitioning of care from hospital to home can at times be a challenging task for patients and caregivers. The often-hasty transition process may lead to quality and safety problems contributing to unnecessary emergency department visits and hospital readmissions. Patients often do not have a good understanding of their medication instructions, self-care techniques, how to identify symptoms to report, or the importance of timely follow-up with their health-care provider. Postdischarge nurse triage facility and follow-up calls by health-care providers allow patients and families to verbalize their concerns and issues over the phone. By connecting with patients, the organization may reduce costly

This is an open access journal, and articles are distributed under the terms of the Creative Commons Attribution-NonCommercial-ShareAlike 4.0 License, which allows others to remix, tweak, and build upon the work non-commercially, as long as appropriate credit is given and the new creations are licensed under the identical terms.

For reprints contact: WKHLRPMedknow_reprints@wolterskluwer.com readmissions, intercept possible unfavorable incidents, and increase patient satisfaction. ${ }^{[1]}$

\section{Methods}

The project was implemented after a tedious process involving needs assessment, defining and allocating resources, categorizing the scope of the service, developing categories of patients according to acuity level and developing disposal guidelines for each category, developing an algorithm for dealing incoming hotline calls, developing a standardized tool for postdischarge phone calls, developing job description and training requirements for the dedicated hotline nurses, designing a system for maintaining patient records, and sharing

How to cite this article: Bibi S, Mitha R, Bano K, Datoo F, Karim N, Shamim MS. Postdischarge 24/7 hotline service for neurology and neurosurgery patients and 1-year impact on readmission rates, unplanned emergency department visits, and patient satisfaction. Asian J Neurosurg 2021;16:312-5.

Submitted: 23-Oct-2020

Accepted: 04-Feb-2021

Revised: 02-Jan-2021 Published: 28-May-2021

\section{Shafqat Bibi, Rida Mitha ${ }^{1}$, Kiran Bano, Farida Datoo, Nadia Karim, Muhammad Shahzad Shamim ${ }^{1}$}

Department of Nursing Services, The Aga Khan University Hospital, ' Department of Surgery, Section of Neurosurgery, The Aga Khan University Hospital, Karachi, Pakistan

\begin{abstract}
Address for correspondence:
Dr. Muhammad Shahzad

Shamim,

Department of Surgery, Section of Neurosurgery, The Aga Khan University Hospital, Karachi, Pakistan.

E-mail: shahzad.shamim@aku.
\end{abstract} edu

Access this article online Website: www.asianjns.org DOI: 10.4103/ajns.AJNS_479_20 Quick Response Code:

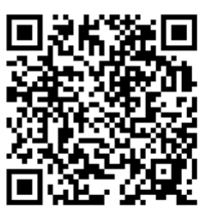


information with all relevant services, i.e., consultants, clinic management staff, and emergency department.

The services included two distinct goals:

1. Telephonic triage system: Each patient was provided with the hotline number at the time of discharge to call in case of any query or emergency. The service was available 24/7, whereby the hotline nurse answered all the queries raised by patients and families

2. Postdischarge follow-up: All discharged patients were contacted within $72 \mathrm{~h}$ of discharge by a member of health-care team.

\begin{tabular}{lccc}
\hline \multicolumn{4}{c}{ Table 1: Categories of calls on hotline } \\
\hline Number of calls & October 2017-December 2017 & $\mathbf{2 0 1 8}$ & $\mathbf{2 0 1 9}$ \\
\hline Urgent & 6 & 25 & 28 \\
Emergent & 302 & 859 & 740 \\
Nonurgent & 44 & 361 & 376 \\
Total & 352 & 1245 & 1144 \\
\hline
\end{tabular}

The postdischarge follow-up call consisted of the following components, assessment of current health status, prescription check, clarification of clinic appointments and laboratory tests, co-ordination of postdischarge home services, and review of warning signs.

The following categories were made to identify the level of care or advice patients required:[Table 1]

- Emergent: Medical care that directly addresses a threat to life or permanent disability. It included chest pain, shortness of breath, decreasing/altering level of consciousness, signs of acute stroke, or any life-threatening symptoms. These patients are advised to visit the emergency department as soon as possible. In such cases, the emergency department is notified of the patients' arrival

- Urgent: When the condition is not life threatening but requires care in a timely manner (within $24 \mathrm{~h}$ ). These patients are advised to visit the emergency department

Table 2: Emergency department visits and readmissions in prehotline period Prehotline period

\begin{tabular}{|c|c|c|c|c|c|c|c|}
\hline Month & $\begin{array}{c}\text { Total } \\
\text { admission }\end{array}$ & $\begin{array}{c}\text { ED visits by } \\
\text { neurology patients }\end{array}$ & $\begin{array}{c}\text { ED visit by } \\
\text { neurosurgery patients }\end{array}$ & $\begin{array}{c}\text { Total ED } \\
\text { visits }\end{array}$ & $\begin{array}{l}\text { Readmission } \\
\text { in neurology }\end{array}$ & $\begin{array}{c}\text { Readmission in } \\
\text { neurosurgery }\end{array}$ & $\begin{array}{c}\text { Total } \\
\text { readmissions }\end{array}$ \\
\hline January 2017 & 303 & 5 & 6 & 11 & 5 & 11 & 16 \\
\hline February 2017 & 274 & 4 & 4 & 8 & 9 & 10 & 19 \\
\hline March 2017 & 309 & 3 & 5 & 8 & 6 & 17 & 23 \\
\hline April 2017 & 284 & 1 & 4 & 5 & 7 & 13 & 20 \\
\hline May 2017 & 326 & 4 & 7 & 11 & 4 & 12 & 16 \\
\hline June 2017 & 249 & 3 & 1 & 4 & 6 & 3 & 9 \\
\hline
\end{tabular}

ED - Emergency department

\begin{tabular}{|c|c|c|c|c|c|c|c|}
\hline \multicolumn{8}{|c|}{ Immediate posthotline period } \\
\hline Month & $\begin{array}{c}\text { Total } \\
\text { admission }\end{array}$ & $\begin{array}{c}\text { ED visits by } \\
\text { neurology patients }\end{array}$ & $\begin{array}{c}\text { Visits to ED } \\
\text { neurosurgery patients }\end{array}$ & $\begin{array}{c}\text { Total ED } \\
\text { visits }\end{array}$ & $\begin{array}{l}\text { Readmission } \\
\text { in neurology }\end{array}$ & $\begin{array}{c}\text { Readmission in } \\
\text { neurosurgery patients }\end{array}$ & $\begin{array}{c}\text { Total } \\
\text { readmission }\end{array}$ \\
\hline October 2017 & 342 & 4 & 2 & 6 & 7 & 3 & 10 \\
\hline November 2017 & 328 & 3 & 4 & 7 & 10 & 10 & 20 \\
\hline December 2017 & 267 & 3 & 6 & 9 & 6 & 8 & 14 \\
\hline January 2018 & 282 & 2 & 4 & 6 & 3 & 14 & 17 \\
\hline February 2018 & 278 & 3 & 5 & 8 & 4 & 7 & 11 \\
\hline March 2018 & 344 & 2 & 3 & 5 & 3 & 7 & 10 \\
\hline
\end{tabular}

ED - Emergency department

Table 4: Emergency department visits and readmissions in late posthotline period

Late posthotline period

\begin{tabular}{|c|c|c|c|c|c|c|c|}
\hline Month & $\begin{array}{c}\text { Total } \\
\text { admission }\end{array}$ & $\begin{array}{c}\text { ED visits by } \\
\text { neurology patients }\end{array}$ & $\begin{array}{c}\text { Visits to ED } \\
\text { neurosurgery patients }\end{array}$ & $\begin{array}{l}\text { Total ED } \\
\text { visits }\end{array}$ & $\begin{array}{l}\text { Readmission } \\
\text { in neurology }\end{array}$ & $\begin{array}{c}\text { Readmission in } \\
\text { neurosurgery patients }\end{array}$ & $\begin{array}{c}\text { Total } \\
\text { readmission }\end{array}$ \\
\hline April 2019 & 289 & 0 & 3 & 3 & 1 & 6 & 7 \\
\hline May 2019 & 232 & 1 & 1 & 2 & 2 & 11 & 13 \\
\hline June 2019 & 251 & 0 & 1 & 1 & 4 & 9 & 13 \\
\hline July 2019 & 300 & 0 & 1 & 1 & 1 & 7 & 8 \\
\hline August 2019 & 294 & 1 & 1 & 2 & 3 & 8 & 11 \\
\hline September 2019 & 281 & 0 & 1 & 1 & 1 & 8 & 9 \\
\hline
\end{tabular}

ED - Emergency department 
within $24 \mathrm{~h}$, or facilitated with appointments on an early basis, or explained nursing care or other related guidelines to treat at home by keeping doctors in knowledge

- Nonurgent: Routine care for stable patients whose condition will not deteriorate over time and/or will typically resolve on its own or the problem is not directly related to patient health. It includes issuing a medical certificate, laboratory orders, appointments, and prescription refills. These patients get facilitated as per need.

We compared 30-day readmission rate and number of emergency room (ER) visits in three categories:

1. Prehotline Period: January 2017-June 2017, when there were no hotline services

2. Immediate posthotline period: October 2017-March 2018. Startup period after initiation of hotline services

3. Late posthotline period: April 2019-September 2019, when hotline services were a part of care for 1.5 years.

One senior registered nurse was assigned to deal with hotline incoming calls and making follow-up discharge calls during the morning hours. She was given an office in our neurosurgery ward in the main hospital building. During the morning hours, the nurse assigned to the hotline was not responsible for any clinical duties of the ward. To provide $24 / 7$ services, during the evening shifts, the team leader was responsible for all incoming calls to the hotline.

\section{Results}

We initiated the hotline in October 2017. From October to December 2017, we received 352 incoming calls and made 772 postdischarge calls of the 929 discharges during that time period.[Table 2] Similarly, in 2018, we received 1245 incoming calls and made 2652 postdischarge calls of the 3392 discharged patients.[Table 3] In 2019, of the 3402 patients discharged, we made 2721 postdischarge follow-up calls and received 1144 calls on the hotline from discharged patients. [Table 4]

On analysis, we found a $25 \%$ decline in readmission rate in the immediate period of hotline followed by a further decline to $37.2 \%$ in the late period as compared to the prehotline period. [Table 5]

Among discharge patients visiting the emergency department, we found a decline of $18.5 \%$ in the immediate posthotline period which further declined to $77.7 \%$ in the later phase as compared to the prehotline period. [Table 6]

Patient satisfaction rate is not directly related to implication of hotline services but indirectly measures patient satisfaction to overall care provision. We have traced these results via institutions quarterly overall patient satisfaction survey report. The cumulative percentages for the years 2017, 2018, and 2019 are 87.45\%, 86.73\%, and $90.6 \%$, respectively. [Table 7] There was a decline of
$0.7 \%$ in patient overall satisfaction rate in the immediate posthotline period, but there was an increase of $3.87 \%$ in the overall patient satisfaction rate in the late posthotline period [Table 7].

\section{Discussion}

In a country like Pakistan where health care is mainly out of pocket, the hotline service can be a useful tool to cut down costs without compromising on patient care and safety. Furthermore, telephone contact with patients after discharge provides a continuum of care. It allows early recognition of problems and avoids unnecessary emergency department visits and readmissions. In 1996, a survey done by Bowman et al. demonstrated the use of a telephone service postdischarge on 85 patients. ${ }^{[2]}$ Of the 85 patients, $48(56 \%)$ reported health problems, $16(19 \%)$ patients

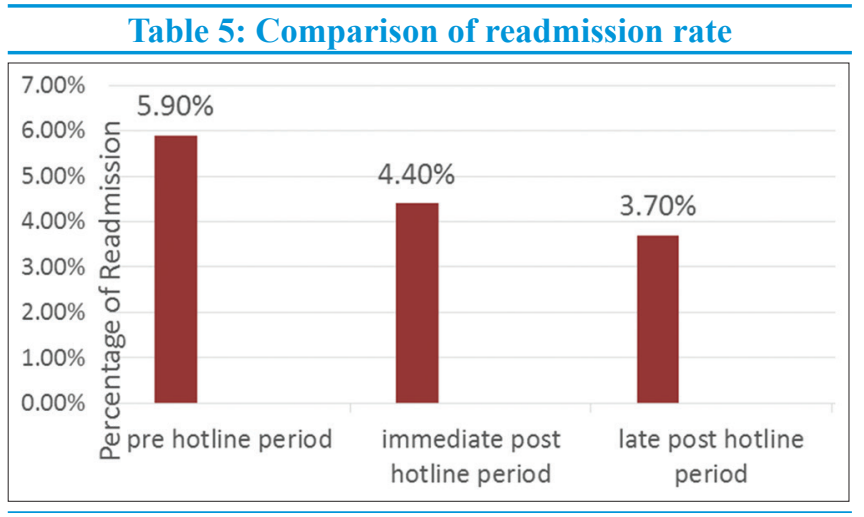

Table 6: Comparison of emergency department visit rate

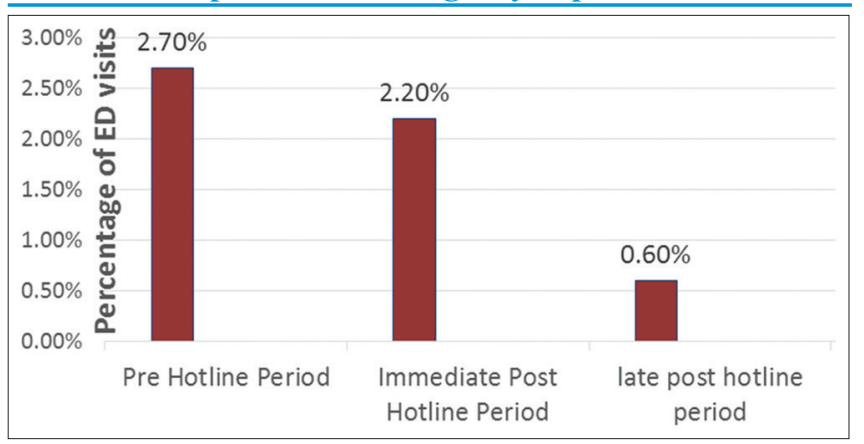

Table 7: Comparison of emergency patient overall satisfaction rate

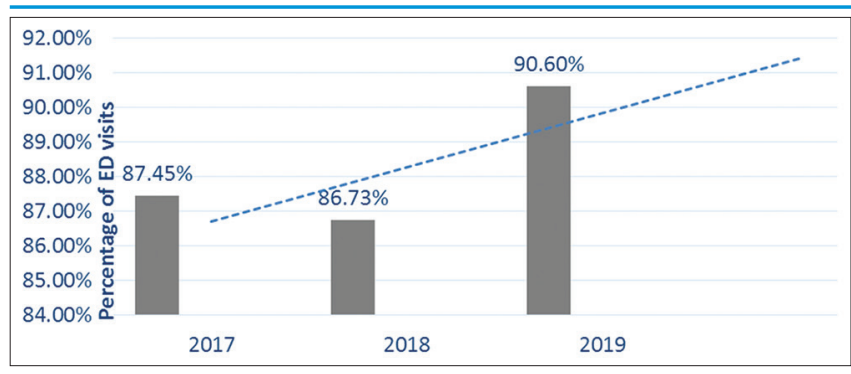

Asian Journal of Neurosurgery | Volume 16 | Issue 2 | April-June 2021 
reported social problems, and $36(42 \%)$ patients sought advice. They concluded that a telephone follow-up could be a useful means of monitoring a patient's progress.

In 1997, Chewitt et al. developed a protocol for a surgical hotline at Victoria General Hospital, Winnipeg, Canada. ${ }^{[3]}$ The questionnaire was developed with the input of the surgeons and was related to 11 major areas of postoperative patient concerns. $57.6 \%$ of the callers were given advice by hotline nurses while the remainder were directed to the emergency department, told to call their surgeon, or a combination of all three. Eighty-five percent of the patients calling the hotline felt that it was a positive factor in their recovery process. Of the callers surveyed, $85 \%$ stated that the hotline met their needs, and $98 \%$ claimed that they would recommend the hotline to other postsurgical patients. Comments from callers also indicated that advice from hotline nurses prevented unnecessary visits to the emergency department.

In Lothian, a region of Scotland, a quality improvement report conducted by Kerr et al., in 2010, used a telephone hotline for transient ischemic attack and stroke to improve rapid access to specialist stroke care. ${ }^{[4]}$ They concluded that the stroke hotline resulted in a significant reduction in delays to assessment and an increase in the proportion of patients started on appropriate medication after an ischemic event for secondary prevention.

A hotline service has time and again shown to benefit patients positively cutting down costs for patients and the burden on the health-care system, as it results in decreased visits to the ER. In a health-care system like Pakistan, which is constantly overburdened, the hotline service results in fewer readmissions for problems that can be managed at home or in outpatient clinics. This allows more beds available for patients with medical problems that require hospital admissions.

Components of this project were challenging to implement in acute health-care settings because hotline nurses in clinical hours, i.e., from Monday through Friday, efficiently handled call volume, and determine the disposition of care to ensure that the patient is being responded to the call and the query is resolved. Yet, in evenings, nights, weekends, and public holidays, the team leader in service line is responsible to provide the services. The team leaders are at times busy in areas, which makes it difficult for them to timely respond. Although there were many limitations in the implementation of the services, so far, no additional staff members were hired to implement these changes.

By looking at frequency of incoming calls at hotline and categories of patient complaints, we suggest to improve patient discharge instructions by reinforced discharge teachings and patient discharge checklist to ensure patients and families are provided with enough information to strengthen transition in care.

\section{Conclusion}

Implementing a telephone triage system can help improve health outcomes for many patients. The telephone triage system can not only reduce unnecessary ER visits and lower costs, but also it can help people who actually need to go to the ER by assessing emergent and urgent patient phone calls and potentially improve patient and caregiver satisfaction. This also identifies opportunities for providers and hospital systems to adopt discharge improvement initiatives.

\section{Financial support and sponsorship}

Nil.

\section{Conflicts of interest}

There are no conflicts of interest.

\section{References}

1. Meek KL, Williams P, Unterschuetz CJ. Outsourcing an effective post-discharge call program. A collaborative approach. Nurs Adm Q 2018;42:175-9.

2. Bowman GS, Howden J, Allen S, Webster RA, Thompson DR. A telephone survey of medical patients 1 week after discharge from hospital. J Clin Nurs 1994;3:369-73.

3. Chewitt MD, Fallis WM, Suski MC. The surgical hotline. Bridging the gap between hospital and home. J Nurs Adm 1997;27:42-9.

4. Kerr E, Arulraj N, Scott M, McDowall M, van Dijke M, Keir S, et al. A telephone hotline for transient ischaemic attack and stroke: Prospective audit of a model to improve rapid access to specialist stroke care. BMJ 2010;341:c3265. 